\title{
Satisfaction and Mental Health Outcomes Associated with a Large Regional Helpline
}

\author{
Sean R. McClellan ${ }^{1}$ (D) Meaghan Hunt ${ }^{1} \cdot$ Lauren E. W. Olsho ${ }^{1} \cdot$ Amrita Dasgupta $^{2} \cdot$ Mifta Chowdhury $^{2} \cdot$ \\ Alicia C. Sparks ${ }^{1}$
}

Received: 1 July 2021 / Accepted: 17 December 2021 / Published online: 11 January 2022

(c) The Author(s), under exclusive licence to Springer Science+Business Media, LLC, part of Springer Nature 2022

\begin{abstract}
We surveyed users of a behavioral health helpline serving New York City and surroundings, to assess their helpline experiences, changes in psychological distress after contacting the helpline, and factors associated with differences in these measures. We surveyed users twice: roughly 2 weeks following their helpline contact, from 4/2019 to 9/2019 ( $N=1097$ respondents) and again 6 months following contact, from 10/2019 to 3/2020 ( $\mathrm{N}=732$ respondents). Eighty-nine percent of respondents reported that contacting the helpline helped them deal a little or a lot more effectively with their problems. Rates of psychological distress decreased from $41.3 \% 2$ weeks following helpline contact to $29.0 \% 6$ months after $(\mathrm{P}<0.05)$. Improvements in psychological distress were found across a range of demographic characteristics and were greatest for repeat users. Users reported broadly positive experiences with the helpline and improved psychological distress 6 months later. Behavioral health helplines can offer beneficial services to diverse populations, complementing the formal behavioral healthcare system.
\end{abstract}

Keywords Helpline $\cdot$ Care experience $\cdot$ Psychological distress $\cdot$ Survey research $\cdot$ Behavioral health

\section{Introduction}

According to the 2018 National Survey on Drug Use and Health, approximately $19 \%$ of U.S. adults (47.6 million) reported experiencing mental illness in the past year (Substance Abuse \& Mental Health Services Administration, 2019). Fewer than half of these (20.6 million, or $43 \%$ ) indicated receiving mental health services during that timeframe (Substance Abuse \& Mental Health Services Administration, 2019). Likewise, roughly $8 \%$ of U.S. adolescents and adults reported a substance use disorder or needing substance use treatment (21.2 million), but only 3.7 million (17\%) received substance use treatment in the past year (Substance Abuse $\&$ Mental Health Services Administration, 2019). Additionally, many individuals experience sub-threshold but clinically significant mental health distress that could benefit

Sean R. McClellan

Sean_McClellan@abtassoc.com

1 Division of Health and Environment, Abt Associates, 10 Fawcett St., Cambridge, MA 02138, USA

2 NYC Health + Hospitals, 125 Worth St., New York, NY 10013, USA from intervention (Prochaska et al., 2012). Individuals in need may not engage with formal behavioral health services for many reasons, including stigma, expense, inability to find a provider, or linguistic or cultural barriers (Clement et al., 2015; Mechanic, 2002; Mojtabai, 2005; Mojtabai et al., 2011).

Behavioral health helplines (also called hotlines, lifelines, warmlines, or crisis lines) assist individuals who may not use other behavioral health services or who need immediate support (Middleton et al., 2016). Thousands of helplines exist worldwide, many serving specific geographic areas (e.g., countries, states, or metropolitan areas). Helplines provide a variety of services, including short-term counseling, suicide prevention or other crisis intervention, peer support, information and referral, and follow-up services (Gould et al., 2012; Ramchand et al., 2017; Shor \& Birnbaum, 2012), and often serve specific populations, such as veterans or adolescents (Dalgin et al., 2011; Knox et al., 2012; Price et al., 2016). Helplines may also be a starting point for receiving referrals to behavioral health providers and accessing services (Coveney et al., 2012; Gould et al., 2007; Kalafat et al., 2007; Middleton et al., 2016). In October 2020, the US federal government passed The National Suicide Hotline Designation Act, which 
created a national suicide prevention and mental health crisis hotline system that can be accessed nationally using a threedigit number (988), instead of the 10-digit number used previously (U.S. Government Publishing Office, 2020).

Studies of helplines have found high satisfaction (Biggs et al., 2015; Britton et al., 2013; Coveney et al., 2012) and suggest helpline use is associated with reduced suicidality (Gould et al., 2007, 2018), distress (Ramchand et al., 2017), and hopelessness (Gould et al., 2007; Kalafat et al., 2007). However, few studies have assessed differences in helpline experiences across user demographic characteristics (Gould et al., 2018), and most studies focused on users' short-term experiences and psychological states, such as during the contact (Biggs et al., 2015) or within the subsequent 2-3 weeks (Gould et al., 2007, 2012; Kalafat et al., 2007; Millstein, 2009). Limited research exists on longer-term user mental health status outcomes after helpline contact (Dalgin et al., 2018; Gould et al., 2018), and small sample sizes have limited assessment of outcomes among diverse subpopulations.

This study builds on a longitudinal survey of users of NYC Well, a behavioral health helpline serving New York City (NYC) and surrounding areas, conducted as part of a broader evaluation of NYC Well (Sparks et al., 2020). Launched in October 2016 under a citywide behavioral health initiative overseen by the NYC Mayor's Office, NYC Well is a free and confidential service for New Yorkers seeking emotional support, suicide prevention or other crisis intervention, peer support, information and treatment referral, connection to mobile crisis teams, and follow-up services for behavioral health concerns. NYC Well helpline operators, which include both counselors and Peer Support Specialists, serve a large and diverse population of over 200,000 users each year (NYC Mayor's Office of Operations, 2020). Counselors and Peer Support Specialists go through a 2- to 3-week training period that includes detailed discussions of protocols and approaches to providing NYC Well's service, role modeling overseen by a trained senior counselor or Peer Support Specialist, and a set of observed interactions with NYC Well users. Users are not always assigned the same operator when they call back. Each call is treated as a "new" call in the phone triage. We surveyed helpline users of NYC Well roughly 2 weeks after contacting the helpline and again 6 months after to assess user experiences and changes in psychological distress, as well as factors associated with user experiences and mental health outcomes.

\section{Methods}

\section{Data}

\section{Survey Sample}

From April 1 to August 4, 2019, helpline providers invited all eligible individuals who contacted NYC Well by phone, text, or online chat to participate in a follow-up survey at the end of their helpline contact. To be eligible to participate, individuals had to be 13 years of age or older and speak English or Spanish. Users were not eligible if they were experiencing an acute behavioral health crisis (e.g., suicidal intent, impaired functioning or psychological distress, as assessed by their helpline provider), or if they were a clinician or service provider contacting the helpline on behalf of a patient or client. While users were eligible to participate no matter their assessed level of psychological distress in the prior month, users contacting the program in acute crisis were excluded due to concerns about the clinical safety and appropriateness of asking these individuals to complete the survey, and their ability to provide informed consent during their service interaction. The survey sample included individuals contacting the program on their own behalf and those contacting on behalf of someone else, although as noted below those contacting on behalf of someone else were excluded from the present analyses. We identified 43,132 unique helpline users making at least one contact during the recruitment period. Of 43,132 unique users contacting the helpline at least once during the study period, 31,460 (73\%) met eligibility criteria, and 2283 users (7\%) agreed to be contacted for the follow-up survey. Helpline providers retained discretion to not invite individuals to participate if not clinically appropriate and did not track when users refused or were unable to participate in the survey (i.e., contact ended abruptly). Among users eligible for the survey, those recruited had more helpline contacts; higher documented mental health risk levels, substance use, and documented suicidal ideation and intent; and more complete administrative data than those who were not recruited (see Supplementary Appendix for additional detail). While users who were recruited for the survey represented only $7 \%$ of all users contacting the helpline during the recruitment period, they accounted for $47 \%$ of the contacts made during the recruitment period. Therefore, while the users who agreed to participate in this study may not be representative of the population served by the helpline overall, they represent an important constituency.

\section{Compliance with Ethical Standards}

Individuals who consented to participate in this study also consented to having their NYC Well administrative records linked to their survey responses for analyses. This study was approved by the REDACTED Institutional Review Board. The supplementary materials provide additional detail on eligibility and recruitment.

\section{Survey Data Collection}

We surveyed NYC Well users about how they learned about the helpline, their experiences with it, recent use of other behavioral health services, self-reported mental health 
status, and demographic characteristics. We contacted consenting NYC Well users for the initial follow-up survey starting 2 weeks after their contact to the helpline, from April to September $2019(\mathrm{~N}=1097$; response rate $=48.1 \%)$, and again 6 months after their helpline contact, from October 2019 to March $2020(\mathrm{~N}=732$; response rate $=68.3 \%)$. We completed data collection before COVID-19 began to escalate in NYC, in March 2020. We fielded both surveys via email with links to a web survey; users who did not respond to the initial email received telephone follow-up. Respondents were provided a $\$ 30$ gift card incentive for participating in the 2-week follow-up survey; a $\$ 5$ incentive for confirming and validating their contact information at 3 months' follow-up; and a $\$ 25$ gift card incentive for completing the six-month follow-up survey.

\section{Administrative Data}

The helpline compiles information for each contact, including a unique user identification number; the date, time, and mode of contact; and user characteristics collected by providers (including demographic characteristics and history of suicidality and drug use). We linked user-level administrative data with the survey sample and survey responses.

\section{Analytic Sample}

This study focused on experiences and self-reported mental health status among helpline users contacting the program on their own behalf. We also limited the analytic sample to respondents providing valid responses to all survey questions used in the multivariate regression analyses, which resulted in the exclusion of 39 respondents. The final analytic sample size for this study was 857 respondents completing the 2-week follow-up survey and 595 completing the six-month follow-up survey.

\section{Measures}

\section{Demographic Characteristics}

We derived demographic information from survey questions included in the survey fielded 2 weeks following helpline contact, including age, gender, race, ethnicity, education, and whether the user had insurance.

\section{Helpline Interaction}

We obtained NYC Well administrative data on number and mode of helpline contacts. The survey asked whether or not users received a referral to or contact information for another provider during their helpline contact (Gould et al., 2012).

\section{Experiences and Satisfaction with Helpline}

We used three measures of experience and satisfaction with the helpline, adapted from a satisfaction survey fielded by NYC Well, collected in the survey fielded 2 weeks following helpline contact: Contacting NYC Well Helped Deal More Effectively with Problems (helped a lot, helped a little, didn't help or hurt, made things a little worse, and made things a lot worse); Satisfaction with Experience with NYC Well (very much satisfied; somewhat satisfied; somewhat dissatisfied; or very dissatisfied); and Would Recommend NYC Well to a Friend in Need of Similar Help (would definitely recommend, would probably recommend; would probably not recommend, and would definitely not recommend).

We created binary analytic measures reflecting the most positive experiences: contact helped deal a lot more effectively with problems (vs a little, no difference, or worse); very satisfied with experience (vs somewhat satisfied or dissatisfied); and would definitely recommend to a friend (vs probably or would not recommend). We used top-box coding for these measures given the distribution of responses (a high proportion of respondents selected the best experience for each measure) and because even the second best response (e.g., probably recommend) indicates that the experience was not entirely positive (Elliott et al., 2009).

\section{Mental Health Status}

In both the 2-week and six-month follow-up surveys, we asked respondents to complete the Kessler 6 Psychological Distress Scale (K6), a six-item series of validated questions assessing psychological distress (Kessler et al., 2003; McGinty et al., 2020). The K6 requires respondents to report how often they felt the following during the past 30 days: nervous; hopeless; restless/fidgety; depressed; that everything was an effort; and worthless. Following the K6 guidelines, we scored each response on a scale from 0 (none of the time) to 4 (all of the time), and summed responses to generate a composite score ranging from 0 to 24 (Kessler et al., 2003). Individuals with scores between 0 and 4 were assessed as having no psychological distress, between 5 and 12 were assessed as having moderate psychological distress, and of 13 or higher were assessed as having serious psychological distress (Kessler et al., 2003).

\section{Analysis}

\section{Survey Weights and Generalizability of the Survey Data}

We used administrative data from the helpline to assess whether sampled users differed from those who were eligible to be recruited but were not; we also assessed 
differences between survey respondents and sampled nonrespondents. In general, survey respondents were similar to non-respondents; however, the survey sample disproportionately represented repeat users and differed across a variety of dimensions, including having a greater share of users with documented substance use and suicidal ideation and intent, relative to users who were not selected for the survey sample. Because of the large magnitude of these differences, incorporating sampling weights introduced an unacceptable degree of imprecision into our analyses. We therefore used non-response weights to account for differences between the population of helpline users recruited to the sample and those who responded to the survey, without incorporating additional sampling adjustment to account for selection into the recruited sample. We calculated two nonresponse weights, both weighting respondents to reflect the entire survey sample: one for all respondents to the 2-week follow-up survey, and one for respondents to both surveys. Weighted analyses of both surveys can be considered representative of the users selected into the survey sample, who made roughly half of the contacts to the helpline during the study period, but not generalizable to the broader population of eligible or all helpline users. Supplementary Appendix B of the supplementary materials includes additional detail.

\section{Summary Statistics}

We used responses from the 2-week follow-up survey to calculate summary statistics on user characteristics, their experiences with the helpline, and changes in mental health status from the 2-week follow-up survey to the six-month follow-up survey. Bivariate differences in demographic characteristics and helpline experiences by level of psychological distress were calculated using chi-squared tests.

\section{Multivariate Analyses}

We used cross-sectional logistic regression to assess factors associated with helpline experiences reported in the 2-week follow-up survey. Dependent variables included binary measures reflecting positive experiences with the helpline. Explanatory measures included age, gender, race, Hispanic ethnicity, education, having health insurance, self-reported level of psychological distress, helpline contact mode, and number of helpline contacts during the study recruitment period.

To assess factors associated with changes in serious psychological distress between two surveys, we used generalized estimating equations (GEE) regression with a probit link to account for repeated observations within users over time (Ballinger, 2004). The dependent variable was serious psychological distress. Explanatory measures included demographic characteristics, mode and number of contacts, and receipt of a referral.

\section{Results}

The helpline served a diverse group of users across several demographic characteristics (Table 1). For example, among users recruited for the study, $37 \%$ of users identified as White, $30 \%$ as Black or African American, $8 \%$ as Asian, and $26 \%$ as other/multiple races; and $26 \%$ identified as Hispanic ethnicity. Among surveyed users, $75 \%$ contacted the helpline more than once, most frequently via telephone (75\%), and $64 \%$ reported receiving a referral during their contact.

Users recruited for the study reported broadly positive experiences interacting with the helpline when initially surveyed 2 weeks following their contact (Table 2). Sixty percent of users reported that their interaction with the helpline helped them deal a lot more effectively with problems, and another $29 \%$ reported that the helpline helped deal a little more effectively with problems. Likewise, nearly $70 \%$ reported being very satisfied with their helpline experience and $74 \%$ reported they would definitely recommend the helpline to a friend in need of similar help.

After adjusting for other user characteristics, users with serious psychological distress were less likely to report that contacting the helpline helped deal a lot more effectively with problems than users with no psychological distress ( $-11 \%$ points; $95 \%$ confidence interval $(\mathrm{CI})-21$ to -2$)$, and users with moderate psychological distress were less likely to report that they would recommend the helpline than users with no psychological distress (-8\% points; $95 \%$ CI - 16 to -0) (Table 3). Additionally, Asian respondents reported consistently worse experiences relative to White respondents, and users interacting only by chat reported consistently worse experiences relative to those who called the hotline. We found no statistically significant differences in experiences between users who did and did not recall receiving a referral to another provider.

Users' self-reported psychological distress improved between the 2-week follow-up survey and the six-month follow-up survey (Table 4). Across all users responding to both surveys, $41 \%$ reported serious psychological distress in the 2 -week follow-up survey, relative to $29 \%$ in the six-month follow-up survey, a decrease of $12 \%$ points (95\% CI -17 to -8$)$. This improvement in psychological distress held across a broad set of demographic subgroups, including age (with the exception of the oldest and youngest users, where findings were not statistically significant), gender, race and ethnicity.

Among the subset of respondents contacting the helpline multiple times, the prevalence of serious psychological distress was reduced between 12 and $21 \%$ points from 2 
Table 1 Characteristics of helpline users

\begin{tabular}{|c|c|}
\hline Characteristics & No. $(\%)$ \\
\hline \multicolumn{2}{|l|}{ Age } \\
\hline $13-17$ & $28(3.7)$ \\
\hline $18-34$ & $480(54.5)$ \\
\hline $35-54$ & $214(25.8)$ \\
\hline $55-64$ & $96(11.3)$ \\
\hline $65+$ & $39(4.7)$ \\
\hline \multicolumn{2}{|l|}{ Gender } \\
\hline Male & $274(34.8)$ \\
\hline Female & $549(61.4)$ \\
\hline Other, transgender, or non-conforming & $34(3.7)$ \\
\hline \multicolumn{2}{|l|}{ Race } \\
\hline White & $316(36.5)$ \\
\hline Black or African American & $259(30.1)$ \\
\hline Asian & 69 (7.9) \\
\hline Other or multiple & $213(25.5)$ \\
\hline Hispanic ethnicity & $219(25.9)$ \\
\hline \multicolumn{2}{|l|}{ Education } \\
\hline Less than high school graduate & $85(10.6)$ \\
\hline High school graduate or some college & 418 (49.7) \\
\hline 4-Year college degree or more & $354(39.8)$ \\
\hline Had health insurance & $733(85.2)$ \\
\hline \multicolumn{2}{|l|}{ Mode of helpline contact } \\
\hline Call only & $622(74.2)$ \\
\hline Chat only & $42(4.4)$ \\
\hline Text/SMS only & $62(6.7)$ \\
\hline Multiple modes & $131(14.7)$ \\
\hline \multicolumn{2}{|l|}{ Number of contacts over roughly 4 month period } \\
\hline 1 & $221(25.8)$ \\
\hline $2-5$ & $342(40.5)$ \\
\hline $6-19$ & $182(21.8)$ \\
\hline $20-99$ & $85(7.9)$ \\
\hline $100+$ & $27(4.0)$ \\
\hline \multicolumn{2}{|l|}{ Receipt of referral to or information for a provider } \\
\hline Did not receive referral to or information for a provider & $303(36.0)$ \\
\hline Received referral to or information for a provider & $554(64.0)$ \\
\hline
\end{tabular}

$\mathrm{N}=857$. Estimates in this table reflect user self-reported characteristics roughly 2 weeks after contact with the helpline and measures from the helpline's administrative data. Surveys were collected from users contacting the helpline between April and August 2019. Estimates are weighted to adjust for survey non-response, such that weighted results can be considered representative of those who were recruited to complete the survey

weeks to 6 months after their helpline contact. In contrast, respondents contacting the NYC Well helpline only once had a lower prevalence of serious psychological distress 2 weeks after their contact, but also reported little change over time (chi-squared test for equality across groups $=13.99$, $\mathrm{P}=0.003)$. There were no statistically significant differences
Table 2 User helpline experiences reported 2 weeks after contacting the helpline

\begin{tabular}{lr}
\hline User helpline experiences & \multicolumn{1}{c}{ No. $(\%)$} \\
\hline $\begin{array}{l}\text { Whether contact helped deal more effectively with } \\
\text { problems }\end{array}$ & $500(59.5)$ \\
Helped a lot & $255(29.2)$ \\
Helped a little & $93(10.5)$ \\
Didn't help or hurt & $8(0.8)$ \\
Little or a lot worse & \\
Satisfaction with experience & $593(69.9)$ \\
Very satisfied & $224(25.7)$ \\
Somewhat satisfied & $39(4.4)$ \\
Somewhat or very dissatisfied & \\
Would recommend to a friend in need of similar help & $634(74.7)$ \\
Definitely yes & $181(21.0)$ \\
Probably yes & $41(4.3)$ \\
Probably or definitely not &
\end{tabular}

$\mathrm{N}=857$. Estimates in this table reflect user self-reported helpline experiences as recalled roughly 2 weeks after contact with the helpline. Surveys were collected from users contacting the helpline between April and August 2019. Estimates are weighted to adjust for survey non-response, such that weighted results can be considered representative of those who were recruited to complete the survey

in degree of improvement by contact mode or by referral receipt, although improvements in serious psychological distress for respondents contacting the helpline by online chat appeared substantially larger in magnitude ( $-30 \%$ points; 95\% CI: -51 to -9$)$ than for users contacting the helpline by other modes. Similarly, though the magnitude of improvement for users receiving referrals $(-14 \%$ points) appeared larger than those for who did not receive a referral $(-9 \%$ points), differences by referral receipt were not statistically significant.

\section{Discussion}

This study assessed self-reported helpline experiences and changes in psychological distress 2 weeks after contacting the helpline and again at 6 months post-contact. Users reported broadly positive experiences with the helpline. The proportion of users reporting serious psychological distress 6 months after contacting the helpline was significantly reduced, relative to follow-up 2 weeks after. These findings may be informative for policymakers and operators of other helplines. NYC Well provides a broad set of services to a large and diverse population, which facilitates meaningful assessments of differences in experiences and psychological distress across user subpopulations.

To our knowledge, this is the first quantitative study with a large sample size to report findings on changes in mental 
Table 3 User characteristics associated with helpline experiences reported 2 weeks after contacting the helpline

\begin{tabular}{|c|c|c|c|}
\hline \multirow[t]{2}{*}{ User characteristics } & \multicolumn{3}{|c|}{ Regression-adjusted percentage point difference relative to reference group (95\% confidence interval) } \\
\hline & $\begin{array}{l}\text { Contact helped deal a lot more } \\
\text { effectively with problems (vs a } \\
\text { little, no difference, or worse) }\end{array}$ & $\begin{array}{l}\text { Very satisfied with experience (vs } \\
\text { somewhat satisfied or dissatisfied) }\end{array}$ & $\begin{array}{l}\text { Would definitely recommend to a } \\
\text { friend (vs probably or would not } \\
\text { recommend) }\end{array}$ \\
\hline \multicolumn{4}{|l|}{ Age (ref: 18-34) } \\
\hline $13-17$ & $4.1(-18.5$ to 26.6$)$ & $-9.2(-31.9$ to 13.5$)$ & $-23.6(-48.5$ to 1.3$)$ \\
\hline $35-54$ & $2.9(-5.3$ to 11.2$)$ & $2.2(-5.2$ to 9.6$)$ & $1.4(-5.6$ to 8.5$)$ \\
\hline $55-64$ & $4.1(-7.2$ to 15.3$)$ & $-6.4(-17.7$ to 4.9$)$ & $2.3(-7.5$ to 12.1$)$ \\
\hline $65+$ & $-1.6(-19.5$ to 16.2$)$ & $-13.4(-31.4$ to 4.6$)$ & $-5.3(-21.8$ to 11.3$)$ \\
\hline \multicolumn{4}{|l|}{ Gender (ref: female) } \\
\hline Male & $-5.2(-12.7$ to 2.2$)$ & $-5.1(-12.2$ to 2.1$)$ & $-2.8(-9.3$ to 3.7$)$ \\
\hline $\begin{array}{l}\text { Other, transgender, or non- } \\
\text { conforming }\end{array}$ & $-1.9(-19.8$ to 15.9$)$ & $-2.7(-17.8$ to 12.3$)$ & $-18.6(-36.2 \text { to }-1.1)^{*}$ \\
\hline \multicolumn{4}{|l|}{ Race (ref: White) } \\
\hline Black or African American & $-0.1(-8.8$ to 8.5$)$ & $5.0(-3.0$ to 13.0$)$ & $6.5(-0.8$ to 13.8$)$ \\
\hline Asian & $-21.7(-35.5 \text { to }-7.8)^{*}$ & $-10.5(-24.4$ to 3.3$)$ & $-14.1(-27.4 \text { to }-0.7)^{*}$ \\
\hline Other or multiple & $-0.2(-9.5$ to 9.2$)$ & $2.5(-6.7$ to 11.7$)$ & $-1.1(-10.1$ to 7.8$)$ \\
\hline Hispanic (ref: not Hispanic) & $0.2(-8.3$ to 8.7$)$ & $-1.3(-9.9$ to 7.2$)$ & $9.9(2.6 \text { to } 17.2)^{*}$ \\
\hline \multicolumn{4}{|l|}{$\begin{array}{l}\text { Education (ref: high school/some } \\
\text { college) }\end{array}$} \\
\hline Less than high school graduate & $4.5(-8.5$ to 17.4$)$ & $7.6(-3.5$ to 18.7$)$ & $16.7(8.5 \text { to } 25.0)^{*}$ \\
\hline 4-Year college degree or more & $-5.6(-12.9$ to 1.8$)$ & $-0.8(-7.8$ to 6.3$)$ & $-0.9(-7.4$ to 5.7$)$ \\
\hline Had health insurance (ref: none) & $-3.6(-13.1$ to 5.8$)$ & $0.6(-8.4$ to 9.6$)$ & $0.2(-8.5$ to 8.8$)$ \\
\hline \multicolumn{4}{|l|}{ Psychological distress (ref: no) } \\
\hline Moderate psychological distress & $-8.6(-17.9$ to 0.8$)$ & $-7.5(-16.2$ to 1.3$)$ & $-8.4(-16.4 \text { to }-0.3)^{*}$ \\
\hline Serious psychological distress & $-11.2(-20.6 \text { to }-1.7)^{*}$ & $-6.4(-15.1$ to 2.3$)$ & $-6.8(-14.8$ to 1.3$)$ \\
\hline \multicolumn{4}{|l|}{$\begin{array}{l}\text { Mode of helpline contact (ref: call } \\
\text { only) }\end{array}$} \\
\hline Chat only & $-31.5(-47.0 \text { to }-16.0)^{*}$ & $-32.2(-49.3 \text { to }-15.2)^{*}$ & $-13.3(-29.1$ to 2.5$)$ \\
\hline Text/SMS only & $-2.4(-15.7$ to 10.8$)$ & $-7.4(-20.2$ to 5.4$)$ & $-4.9(-16.9$ to 7.0$)$ \\
\hline Multiple modes & $-2.3(-12.0$ to 7.4$)$ & $-4.4(-13.6$ to 4.9$)$ & $0.5(-7.7$ to 8.8$)$ \\
\hline \multicolumn{4}{|l|}{$\begin{array}{l}\text { Number of contacts over roughly } \\
4 \text { months (ref: } 1 \text { ) }\end{array}$} \\
\hline $2-5$ & $-0.8(-9.6$ to 7.9$)$ & $-2.6(-11.1$ to 5.9$)$ & $2.9(-5.2$ to 10.9$)$ \\
\hline $6-19$ & $7.6(-2.4$ to 17.6$)$ & $2.5(-6.8$ to 11.9$)$ & $10.1(1.3 \text { to } 18.8)^{*}$ \\
\hline $20+$ & $6.6(-5.5$ to 18.6$)$ & $5.5(-5.4$ to 16.4$)$ & $7.4(-3.2$ to 18.1$)$ \\
\hline $\begin{array}{l}\text { Receipt of referral to or informa- } \\
\text { tion for a provider }\end{array}$ & $-1.7(-9.0$ to 5.6$)$ & $2.2(-4.9$ to 9.3$)$ & $2.5(-4.2$ to 9.1$)$ \\
\hline $\mathrm{N}$ & 857 & 857 & 857 \\
\hline F-value & 1.8 & 1.6 & 2.5 \\
\hline $\mathrm{P}$-value from F-test & 0.011 & 0.046 & $<0.001$ \\
\hline
\end{tabular}

Estimates in this table reflect user self-reported characteristics and helpline experiences 2 weeks after contact with the helpline. Surveys were collected from users contacting the helpline between April and August 2019. Estimates are weighted to adjust for survey non-response, such that weighted results can be considered representative of those who were recruited to complete the survey

$* \mathrm{P}<0.05$

health status 6 months after contacting a helpline. Our finding of improved psychological distress between 2 weeks and 6 months after helpline contact is consistent with other studies reporting improvements in mental health status (including suicidality) within a few weeks of contacting helplines
(Gould et al., 2007, 2018; Kalafat et al., 2007). While Dalgin et al. (2018) found no statistically significant differences over time in the Recovery Assessment Scale, a measure designed to assess community integration, among helpline callers in a follow-up survey conducted longitudinally over 
Table 4 Changes in proportion of respondents with serious psychological distress from 2 weeks after helpline contact and 6 months later

\begin{tabular}{|c|c|c|c|c|c|}
\hline Population & $\mathrm{N}$ & $\begin{array}{l}\text { Two-week } \\
\text { follow-up } \\
\text { survey, } \%\end{array}$ & $\begin{array}{l}\text { Six-month } \\
\text { follow-up } \\
\text { survey, } \%\end{array}$ & $\begin{array}{l}\text { Difference in serious psycho- } \\
\text { logical distress, percentage } \\
\text { points }\end{array}$ & $\begin{array}{l}\text { 95\% Confidence interval for } \\
\text { difference, percentage points }\end{array}$ \\
\hline Overall & 595 & 41.3 & 29.0 & -12.3 & -16.8 to $-7.8^{*}$ \\
\hline \multicolumn{6}{|l|}{ Age } \\
\hline $13-17$ & 16 & 56.1 & 60.2 & 4.1 & -25.8 to 34.0 \\
\hline $18-34$ & 336 & 48.7 & 32.9 & -15.9 & -22.1 to $-9.6^{*}$ \\
\hline $35-54$ & 154 & 37.3 & 27.6 & -9.8 & -18.7 to $-0.8^{*}$ \\
\hline $55-64$ & 66 & 24.9 & 11.7 & -13.2 & -24.3 to $-2.1 *$ \\
\hline $65+$ & 23 & 12.4 & 21.5 & 9.1 & -12.2 to 30.5 \\
\hline \multicolumn{6}{|l|}{ Gender } \\
\hline Male & 187 & 39.6 & 26.4 & -13.2 & -21.0 to $-5.4^{*}$ \\
\hline Female & 382 & 41.9 & 29.9 & -12.0 & -18.1 to $-6.0^{*}$ \\
\hline Other, transgender, or non-conforming & 26 & 47.1 & 39.9 & -7.2 & -20.4 to 6.0 \\
\hline \multicolumn{6}{|l|}{ Race } \\
\hline White & 224 & 46.7 & 35.0 & -11.7 & -19.6 to $-3.9^{*}$ \\
\hline Black or African American & 183 & 34.2 & 27.3 & -6.8 & -15.2 to 1.6 \\
\hline Asian & 44 & 38.8 & 25.9 & -13.0 & -33.4 to 7.5 \\
\hline Other or multiple & 144 & 42.8 & 23.8 & -19.0 & -28.2 to $-9.8^{*}$ \\
\hline \multicolumn{6}{|l|}{ Ethnicity } \\
\hline Not Hispanic & 443 & 43.8 & 29.8 & -14.0 & -19.1 to $-8.8^{*}$ \\
\hline Hispanic & 152 & 34.7 & 26.8 & -7.8 & -18.4 to 2.7 \\
\hline \multicolumn{6}{|l|}{$\begin{array}{l}\text { Number of contacts over roughly } \\
4 \text { months }\end{array}$} \\
\hline 1 & 142 & 33.9 & 36.4 & 2.6 & -7.4 to 12.5 \\
\hline $2-5$ & 250 & 44.6 & 23.5 & -21.1 & -28.3 to $-13.8^{*}$ \\
\hline $6-19$ & 119 & 42.8 & 30.6 & -12.2 & -22.0 to $-2.4^{*}$ \\
\hline $20+$ & 84 & 43.8 & 29.1 & -14.7 & -26.7 to $-2.7^{*}$ \\
\hline \multicolumn{6}{|l|}{ Mode } \\
\hline Call only & 426 & 41.7 & 30.0 & -11.7 & -17.1 to $-6.2^{*}$ \\
\hline Chat only & 26 & 44.2 & 14.3 & -29.9 & -51.0 to $-8.8^{*}$ \\
\hline Text/SMS only & 44 & 28.0 & 20.0 & -8.0 & -23.5 to 7.5 \\
\hline Multiple modes & 99 & 44.5 & 34.1 & -10.5 & -20.9 to 0.0 \\
\hline \multicolumn{6}{|l|}{$\begin{array}{l}\text { Receipt of referral to or information for } \\
\text { a provider }\end{array}$} \\
\hline Did not receive referral & 237 & 40.0 & 31.4 & -8.6 & -16.7 to $-0.5^{*}$ \\
\hline Received referral & 495 & 42.0 & 27.6 & -14.4 & -20.2 to $-8.6^{*}$ \\
\hline
\end{tabular}

Estimates in this table reflect user self-reported characteristics and psychological distress 2 weeks and 6 months after contact with the helpline. Surveys were collected from users contacting the helpline between April and August 2019. Estimates are weighted to adjust for survey non-response, such that weighted results can be considered representative of those who were recruited to complete the survey. $\mathrm{F}$ value $=98.3$ $(\mathrm{P}<0.001)$

$* \mathrm{P}<0.05$

3 years, the study had a sample size of only 48 unique respondents. Users contacting the helpline multiple times and by internet chat or phone reported the greatest improvements in psychological distress; in contrast, users contacting the helpline only a single time or only by texting reported relatively lower improvements in psychological distress. To the extent feasible, helplines might explore the feasibility of facilitating repeated exchanges or deeper relationships with users. Users who received a referral to another provider also reported greater improvement in psychological distress than those who did not. Although the findings about call mode and receipt of referrals were not powered to detect statistically significant differences, these findings nonetheless offer insight to NYC Well and other helplines about which types of interactions are most beneficial. However, these improvements cannot be causally attributed to helpline use and many 
factors may have contributed to these improvements over that timeframe.

This study found that NYC Well users were satisfied with their helpline interactions. Most users reported that the helpline helped deal more effectively with problems, that they were satisfied with their overall experience, and that they would recommend the service to a friend. This is consistent with several other studies of helpline satisfaction (Biggs et al., 2015; Coveney et al., 2012; King, 1977; Millstein, 2009). While estimates of helpline satisfaction may be influenced by acquiescence bias (Millstein, 2009), helpline users may often contact helplines at a low point in their lives, and users across multiple studies and helplines have consistently reported positive experiences.

Both user experiences and improvement in self-reported psychological distress varied by demographic characteristics. Asian respondents reported consistently worse experiences relative to White respondents. These findings may reflect cultural differences in helpline use (Sue et al., 2012) and in how people respond to care experience surveys (Chung et al., 2016; Mayer et al., 2016). Additionally, relative to users reporting no psychological distress roughly 2 weeks following helpline contact, users reporting moderate or serious psychological distress were less likely to report positive experiences with the helpline. Users with moderate or serious psychological distress may have had more complex needs than those with no distress, which helplines may not be able to fully address during a single interaction.

Roughly three-quarters of users exclusively contacted the helpline via phone call, and $15 \%$ used multiple modes; relatively few users used only text or chat to contact the helpline. However, those users interacting only by chat reported consistently worse experiences relative to users who called the helpline. While offering chat may expand access to services, users contacting the helpline by chat may experience delayed response times relative to users contacting the helpline by phone, which could be a factor in explaining the relatively worse experiences reported by those users (Brody et al., 2020; Predmore et al., 2017). As helplines increasingly add online chat options, determining best practices for providing high quality interactions and needed care may be an important implementation consideration. Notably, while users contacting the helpline via chat and text would face similar delays in response times, text users reported similar experiences to call-only and multi-mode users; it is possible that users contacting the helpline by text (on a mobile phone) had an easier time multitasking between responses than users contacting the helpline via online chat.

These findings suggest opportunities for future research. First, few studies have examined the effects of using helplines beyond 6 weeks; an improved understanding of whether and how helplines promote longer term benefits for users would inform how helplines fit into the behavioral health system and help policymakers and helpline operators allocate resources more efficiently. For example, to what extent do helplines substitute vs. complement other behavioral health services, including outpatient therapy, urgent/ emergent care, and care in inpatient settings? Research should consider how helplines — which by their very nature offer virtual, open access to behavioral health supports, typically on a 24/7 basis-are responding to and providing services during natural disasters or public health emergencies, when sectors of the formal behavioral healthcare system may be less accessible. Second, another important opportunity for future research is to better understand differences in helpline experiences and outcomes by race and ethnicity and the reasons for those differences. For example, are there approaches or strategies helplines can implement to improve their cultural or linguistic competencies? Third, identifying a valid comparison group poses unique challenges for studies of helplines, at least in part because the most important factors associated with the decision to use a helpline may not be available to researchers. Nonetheless, future research should consider whether it might be feasible to identify a comparison group for studies of helplines using administrative data, such as Medicaid claims/encounters or electronic health record data, especially in the context of a natural experiment (e.g., a helpline becoming active in one state or region at a given time, but not another state or region). The implementation of the National Suicide Hotline Designation Act of 2020 may provide a unique opportunity for such a study (Substance Abuse and Mental Health Services Administration, 2021).

This study has limitations. First, its findings cannot be interpreted causally. This study reports findings from a survey of helpline users following their contact to the helpline; it was not possible to identify and survey a similar comparison group of non-users or to survey users prior to their helpline contact, and other factors outside of NYC Well that we were not able to control for could have contributed to decreases in psychological distress (e.g., receiving behavioral health care from other providers, time to recover from an acute behavioral health episode). We were not able to obtain information about other activities individuals took after contacting the hotline that may have contributed to their change in distress. However, this study provides important context about the value of the helpline among users of the helpline, including across diverse populations. Second, survey respondents were not representative of all helpline users. As discussed in the methods section, exclusion criteria were applied when initially asking helpline users for consent to participate in the evaluation survey. Additionally, helpline users who consented to participate in the survey differed from eligible users who did not consent. Relative to those who did not consent to participate, recruited participants had more helpline contacts and higher documented 
risk of substance use and suicidal ideation and intent (Supplementary Appendix B). However, while the users who were recruited for the survey represented only about $7 \%$ of all helpline users during the study recruitment period, they accounted for $47 \%$ of helpline contacts during that time and response rates to follow-up surveys among users who agreed to participate in the study were relatively high, $48 \%$ for the first follow-up survey and $68 \%$ for the second follow-up survey. Third, some subgroups had small sample sizes, including the youngest and oldest age groups, Asian respondents, and respondents identifying as other gender, transgender, or gender non-conforming. This limited our ability to identify statistically significant differences of small and moderate magnitudes involving these groups. Fourth, we were not able to identify and collect survey responses from NYC Well users prior to or immediately after their helpline contact, and it is possible that the behavioral health status of users may have changed between the time they contacted the helpline and when they responded to the 2-week follow-up survey. As the survey used multiple modes (email and phone) and was collected by a third-party evaluator rather than helpline staff, workflows did not allow for immediate follow-up, and we were not able to identify users for a potential baseline survey until they made contact with the helpline. However, follow-up surveys even months after an encounter are common, especially for surveys about experiences with health care services (Elliott et al., 2009; Trombley et al., 2019). Additionally, the primary behavioral health outcome used by the study was the Kessler 6 measure of psychological distress, which asks respondents to report how often they felt adverse symptoms during the past 30 days, and which included the period when users contacted the helpline.

Our study of the NYC Well program suggests that behavioral health helplines play an important part of the behavioral health care system, reaching diverse communities and providing counseling and other supports to individuals in need, many of whom report symptoms of moderate to serious psychological distress. Those who contact helplines such as NYC Well may find the services they receive help them manage their problems and reduce distress. The virtual and 24/7 access provided by helplines may be especially critical during the natural disasters and public health emergencies like the COVID-19 pandemic, when the formal behavioral healthcare system may be less accessible and anxiety levels and social isolation may be heightened (Costa et al., 2020). Helplines may also offer an important alternative to using emergency services, along with other resources such as mobile crisis response (Fendrich et al., 2019) or referrals to other mental health services.

Supplementary Information The online version contains supplementary material available at https://doi.org/10.1007/s10597-021-00931-5.
Acknowledgements We acknowledge Farhad Siraj, formally with the Abt Associates Data Science and Enabling Technologies (DSET) Division, for assistance with survey data collection. We acknowledge Anna Robinson of Abt Associates for assistance with the literature review. We thank Jacob Klerman and the Abt Associates Work In Progress Seminar (WIPS) for helpful comments.

Author Contributions SM led design and execution of the quantitative analyses and their write-up. MH managed the study and supported the analyses and writing. LO conceived of and supervised the study. AD and MC managed the study on behalf of the NYC Mayor's Office of Economic Opportunity and provided technical direction and feedback on analytic results and writing. AS led the study and supported writing.

Funding This work was funded by the NYC Mayor's Office of Economic Opportunity. We also acknowledge funding from the Abt Associates Work In Progress Seminar (WIPS) to conduct additional analyses and finalize the manuscript.

\section{Declarations}

Conflict of interest While this work was funded by the NYC Mayor's Office, this study was conducted independently. Although the NYC Mayor's Office retains a contractual right to review the results and conclusion of manuscripts for consistency with publicly available results, it has not censored any results or conclusions. At the time the study was conducted, Amrita Dasgupta and Mifta Chowdhury were with the NYC Mayor's Office for Economic Opportunity. We report no other conflicts of interest.

Ethical Approval This study was approved by the Abt Associates Institutional Review Board.

Informed Consent Individuals who consented to participate in this study also consented to having their NYC Well administrative records linked to their survey responses for analyses.

\section{References}

Ballinger, G. (2004). Using generalized estimating equations for longitudinal data analysis. Organizational Research Methods, 7(2), $127-150$.

Biggs, L. J., Shafiei, T., Forster, D. A., Small, R., \& McLachlan, H. L. (2015). Exploring the views and experiences of callers to the PANDA Post and Antenatal Depression Association Australian National Perinatal Depression Helpline: A cross-sectional survey. BMC Pregnancy and Childbirth, 15, 209. https://doi.org/10.1186/ s12884-015-0594-0

Britton, P. C., Bossarte, R. M., Thompson, C., Kemp, J., \& Conner, K. R. (2013). Influences on call outcomes among veteran callers to the National Veterans Crisis Line. Suicide and Lifethreatening Behavior, 43(5), 494-502. https://doi.org/10.1111/sltb.12033

Brody, C., Star, A., \& Tran, J. (2020). Chat-based hotlines for health promotion: a systematic review. Mhealth, 6, 36. https://doi.org/ 10.21037/mhealth-2019-di-13

Chung, S., Johns, N., Zhao, B., Romanelli, R., Pu, J., Palaniappan, L. P., \& Luft, H. (2016). Clocks moving at different speeds: Cultural variation in the satisfaction with wait time for outpatient care. Medical Care, 54(3), 269-276. https://doi.org/10.1097/MLR. 0000000000000473

Clement, S., Schauman, O., Graham, T., Maggioni, F., Evans-Lacko, S., Bezborodovs, N., Morgan, C., Rusch, N., Brown, J. S., \& Thornicroft, G. (2015). What is the impact of mental health-related 
stigma on help-seeking? A systematic review of quantitative and qualitative studies. Psychological Medicine, 45(1), 11-27. https:// doi.org/10.1017/S0033291714000129

Costa, M., Pavlo, A., Reis, G., Ponte, K., \& Davidson, L. (2020). COVID-19 concerns among persons with mental illness. Psychiatric Services. https://doi.org/10.1176/appi.ps.202000245

Coveney, C. M., Pollock, K., Armstrong, S., \& Moore, J. (2012). Callers' experiences of contacting a national suicide prevention helpline: Report of an online survey. Crisis, 33(6), 313-324. https:// doi.org/10.1027/0227-5910/a000151

Dalgin, R. S., Dalgin, M. H., \& Metzger, S. J. (2018). A longitudinal analysis of the influence of a peer run warm line phone service on psychiatric recovery. Community Mental Health Journal, 54(4), 376-382. https://doi.org/10.1007/s10597-017-0161-4

Dalgin, R. S., Maline, S., \& Driscoll, P. (2011). Sustaining recovery through the night: Impact of a peer-run warm line. Psychiatric Rehabilitation Journal, 35(1), 65-68. https://doi.org/10.2975/ 35.1.2011.65.68

Elliott, M. N., Zaslavsky, A. M., Goldstein, E., Lehrman, W., Hambarsoomians, K., Beckett, M. K., \& Giordano, L. (2009). Effects of survey mode, patient mix, and nonresponse on CAHPS ${ }^{\circledR}$ hospital survey scores. Health Services Research, 44(2p1), 501-518.

Fendrich, M., Ives, M., Kurz, B., Becker, J., Vanderploeg, J., Bory, C., Lin, H. J., \& Plant, R. (2019). Impact of mobile crisis services on emergency department use among youths with behavioral health service needs. Psychiatric Services (Washington, D. C.), 70(10), 881-887. https://doi.org/10.1176/appi.ps.201800450

Gould, M. S., Kalafat, J., Harrismunfakh, J. L., \& Kleinman, M. (2007). An evaluation of crisis hotline outcomes. Part 2: Suicidal callers. Suicide and Lifethreatening Behavior, 37(3), 338-352. https://doi.org/10.1521/suli.2007.37.3.338

Gould, M. S., Lake, A. M., Galfalvy, H., Kleinman, M., Munfakh, J. L., Wright, J., \& McKeon, R. (2018). Follow-up with callers to the National Suicide Prevention Lifeline: Evaluation of callers' perceptions of care. Suicide and Lifethreatening Behavior, 48(1), 75-86. https://doi.org/10.1111/sltb.12339

Gould, M. S., Munfakh, J. L., Kleinman, M., \& Lake, A. M. (2012). National suicide prevention lifeline: Enhancing mental health care for suicidal individuals and other people in crisis. Suicide and Lifethreatening Behavior, 42(1), 22-35. https://doi.org/10.1111/j. 1943-278X.2011.00068.x

Halford, E. A., Lake, A. M., \& Gould, M. S. (2020). Google searches for suicide and suicide risk factors in the early stages of the COVID-19 pandemic. PLoS ONE, 15(7), e0236777. https://doi. org/10.1371/journal.pone.0236777

Kalafat, J., Gould, M. S., Munfakh, J. L., \& Kleinman, M. (2007). An evaluation of crisis hotline outcomes. Part 1: Nonsuicidal crisis callers. Suicide and Lifethreatening Behavior, 37(3), 322-337. https://doi.org/10.1521/suli.2007.37.3.322

Kessler, R. C., Barker, P. R., Colpe, L. J., Epstein, J. F., Gfroerer, J. C., Hiripi, E., Howes, M. J., Normand, S. L., Manderscheid, R. W., Walters, E. E., \& Zaslavsky, A. M. (2003). Screening for serious mental illness in the general population. Archives of General Psychiatry, 60(2), 184-189. https://doi.org/10.1001/archpsyc. 60.2 .184

King, G. D. (1977). An evaluation of the effectiveness of a telephone counseling center. American Journal of Community Psychology, 5(1), 75-83. https://doi.org/10.1007/BF00884786

Knox, K. L., Kemp, J., McKeon, R., \& Katz, I. R. (2012). Implementation and early utilization of a Suicide Hotline for veterans. American Journal of Public Health, 102(Suppl 1), S29-32. https://doi. org/10.2105/AJPH.2011.300301

Magas, I., Norman, C., Baxter, A., \& Harrison, M. (2020). Impact of COVID-19 on Mental Health in New York City. https://www1. nyc.gov/assets/doh/downloads/pdf/covid/covid-19-mental-healthimpacts-hop.pdf
Mayer, L. A., Elliott, M. N., Haas, A., Hays, R. D., \& Weinick, R. M. (2016). Less use of extreme response options by Asians to standardized care scenarios may explain some racial/ethnic differences in CAHPS Scores. Medical Care, 54(1), 38-44. https://doi.org/10. 1097/MLR.0000000000000453

McGinty, E. E., Presskreischer, R., Han, H., \& Barry, C. L. (2020). Psychological distress and loneliness reported by US adults in 2018 and April 2020. JAMA. https://doi.org/10.1001/jama.2020. 9740

Mechanic, D. (2002). Removing barriers to care among persons with psychiatric symptoms. Health Affairs(Millwood), 21(3), 137-147. https://doi.org/10.1377/hlthaff.21.3.137

Middleton, A., Gunn, J., Bassilios, B., \& Pirkis, J. (2016). The experiences of frequent users of crisis helplines: A qualitative interview study. Patient Education and Counseling, 99(11), 1901-1906. https://doi.org/10.1016/j.pec.2016.06.030

Millstein, D. L. (2009). Predictors of caller feedback evaluations following crisis and suicide hotline calls. New Brunswick: Rutgers.

Mojtabai, R. (2005). Trends in contacts with mental health professionals and cost barriers to mental health care among adults with significant psychological distress in the United States: 1997-2002. American Journal of Public Health, 95(11), 2009-2014. https:// doi.org/10.2105/AJPH.2003.037630

Mojtabai, R., Olfson, M., Sampson, N. A., Jin, R., Druss, B., Wang, P. S., Wells, K. B., Pincus, H. A., \& Kessler, R. C. (2011). Barriers to mental health treatment: Results from the National Comorbidity Survey Replication. Psychological Medicine, 41(8), 1751-1761. https://doi.org/10.1017/S0033291710002291

NYC Mayor's Office of Operations. (2020). The City of New York Mayor's Management Report. Retrieved October 9 from https:// www1.nyc.gov/assets/operations/downloads/pdf/mmr2020/2020_ mmr.pdf

Predmore, Z., Ramchand, R., Ayer, L., Kotzias, V., Engel, C., Ebener, P., Kemp, J. E., Karras, E., \& Haas, G. L. (2017). Expanding suicide crisis services to text and chat. Crisis, 38(4), 255-260. https://doi.org/10.1027/0227-5910/a000460

Price, M., Hides, L., Cockshaw, W., Staneva, A. A., \& Stoyanov, S. R. (2016). Young love: Romantic concerns and associated mental health issues among adolescent help-seekers. Behavioral Science (Basel). https://doi.org/10.3390/bs6020009

Prochaska, J. J., Sung, H. Y., Max, W., Shi, Y., \& Ong, M. (2012). Validity study of the K6 scale as a measure of moderate mental distress based on mental health treatment need and utilization. International Journal of Methods in Psychiatric Research, 21(2), 88-97. https://doi.org/10.1002/mpr.1349

Ramchand, R., Jaycox, L., Ebener, P., Gilbert, M. L., Barnes-Proby, D., \& Goutam, P. (2017). Characteristics and proximal outcomes of calls made to suicide crisis hotlines in california. Crisis, 38(1), 26-35. https://doi.org/10.1027/0227-5910/a000401

Shor, R., \& Birnbaum, M. (2012). Meeting unmet needs of families of persons with mental illness: Evaluation of a family peer support helpline. Community Mental Health Journal, 48(4), 482-488. https://doi.org/10.1007/s10597-012-9504-3

Sparks, A., Hunt, M., McClellan, S., Siraj, F., Robinson, A., Armstrong, K., Manetas, M. A., \& Olsho, L. (2020). NYC well evaluation: Final report. Prepared for: the NYC Mayor's Office of Economic Opportunity. . https://www1.nyc.gov/assets/opportunity/ pdf/evidence/nyc-well-evaluation-final.pdf

Substance Abuse and Mental Health Services Administration. (2019). Key substance use and mental health indicators in the United States: Results from the 2018 National Survey on Drug Use and Health.

Substance Abuse and Mental Health Services Administration. (2021, June 16). SAMHSA Awards Vibrant Emotional Health the Grant to Administer 988 Dialing Code for the National Suicide Prevention 
Lifeline. https://www.samhsa.gov/newsroom/press-announceme nts/202106161430

Sue, S., Yan Cheng, J. K., Saad, C. S., \& Chu, J. P. (2012). Asian American mental health: A call to action. American Psychologist, 67(7), 532-544. https://doi.org/10.1037/a0028900

Trombley, M. J., McClellan, S. R., Kahvecioglu, D. C., Gu, Q., Hassol, A., Creel, A. H., Joy, S. M., Waldersen, B. W., \& Ogbue, C. (2019). Association of Medicare's Bundled Payments for Care
Improvement initiative with patient-reported outcomes. Health Services Research. https://doi.org/10.1111/1475-6773.13159

U.S. Government Publishing Office. (2020). National Suicide Hotline Designation Act of 2020. Public Law No: 116-172.

Publisher's Note Springer Nature remains neutral with regard to jurisdictional claims in published maps and institutional affiliations. 